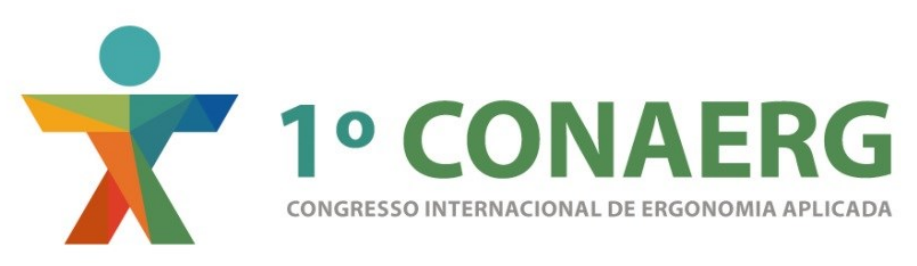

\title{
Academias ao Ar Livre: uma análise dos espaços públicos.
}

\author{
José Alberto Barroso Castañon (1); \\ Claudia dos Reis Paiva (2); \\ Karliane Massari Fonseca (3); \\ Raquel Salgado Carneiro (4).
}

(1) Universidade Federal de Juiz de Fora, Doutor em Engenharia de Transportes.

e-mail: jose.castanon@ufjf.edu.br

(2) Universidade Federal de Juiz de Fora, Mestranda no Programa de pós-graduação em Ambiente Construído.

e-mail: claudiareis_paiva@hotmail.com

(3) Universidade Federal de Juiz de Fora, Mestranda no Programa de pós-graduação em Ambiente Construído.

e-mail: kakamassari@hotmail.com

(4) Universidade Federal de Juiz de Fora, Mestranda no Programa de pós-graduação em Ambiente Construído.

e-mail: raquelrasa@gmail.com

\section{RESUMO}

A implantação de equipamentos de ginástica em espaços públicos procede ao intuito de possibilitar à população qualidade de vida, saúde e lazer. A implantação desses equipamentos em diferentes tipos de espaço e sua utilização por diversificado público gera demanda de atendimento por princípios de design universal, acessibilidade e ergonomia. Buscou-se avaliar a forma de utilização e apropriação dos usuários, além das características que os equipamentos agregam aos espaços em análise, em contrapartida às características que o tipo de espaço público influi no uso dos equipamentos, traçando relações de inserção, manutenção, e infraestrutura que o projeto prevê, com eficiência ou não em seu uso.

\section{ABSTRACT}

The implantation of gym equipments in public spaces proceeds to the intention of making possible to the population health quality and leisure. Utilized by a diversified public, the implantation of these equipments in different types of spaces, generates demands for the principles of universal design, acessibility and ergonomics. We evaluate the way the users utilize and apropriate these equipments, their caracteristics and the way these equipments agregate to the analized areas, in counterpart to the caracteristics that the public spaces influence in the use of these equipments, tracing insertion relations, maintenance and infrastructure that are predicted in the project, being efficient or not. 


\section{DESCRIÇÃO GERAL DO MÉTODO E OBJETIVO}

A seguinte pesquisa se desenvolve a fim de questionar as características que a presença dos equipamentos de ginástica do programa governamental Academia Ao Ar Livre (AAL) agrega ao espaço público, analisando a realidade encontrada desses equipamentos e a adequação espacial qualitativa, relacionando os diferentes tipos de espaço público e o comportamento do usuário com os equipamentos, questionando a influência do entorno nas formas de utilização e averiguando a existência ou não de um tipo específico de público usuário nos diferentes espaços, que proporcione a instalação de equipamentos e infraestrutura direcionados.

O foco se desenvolveu na abordagem da análise espacial através do pressuposto de que "o convívio social no espaço público está intimamente relacionado às oportunidades de acesso e uso" (SUN ALEX, 2011).

Como método de pesquisa foi elaborado levantamento bibliográfico a fim de distinguir os diferentes espaços públicos, as questões de lazer e saúde, assim como definir o que difere a simples instalação de equipamentos de ginástica ao ar livre, das chamadas "academias de saúde e lazer", observando qual modalidade de academia foi implantada nos determinados espaços públicos e como são suas estruturas.

Através de levantamento técnico e coleta de dados, utilizando a análise do discurso, observação participante e entrevistas semiestruturadas, foram realizados apontamentos dos principais fatos observados em três pontos de Juiz de Fora: No Bairro Bom Pastor, Praça Presidente Médici, na Av. Brasil, em trecho que comporta um dos seis conjuntos de equipamentos instalados na via e no Campus da UFJF.

\section{INTRODUÇÃO: A SAÚDE E O LAZER NAS ACADEMIAS AO AR LIVRE}

O lazer (derivado do latim licere, ou seja, "ser lícito", "ser permitido") pode ser entendido como uma maneira do indivíduo utilizar o seu tempo livre. Pode ser entendido em seis áreas fundamentais: os interesses artísticos, os intelectuais, os físicos, os manuais, os turísticos e os sociais (MARCELLINO, 1996).

Como foco da pesquisa, a expressão de lazer analisada será no sentido de interesses físicos, presente em esportes em geral e em todas as atividades físicas, especificamente as atividades realizadas nas academias ao ar livre que, por consequência de uso, envolvem as caminhadas e corridas.

Jogar bola, caminhar, correr, entre outras atividades, podem ser consideradas como práticas de lazer. Os determinismos sociais, políticos, culturais e econômicos pesam nas atividades cotidianas e refletem na escolha do lazer e os limites financeiros inibem realizar algumas das atividades desse contexto configurando um grau de liberdade na escolha (CAMARGO, 2003).

A prática de exercícios em academias de ginástica tem se popularizado, tornando-se a forma mais eficaz de promoção de atividade física, ausente na rotina diária do ser humano. A união das práticas de condicionamento físico ao suporte público de lazer, permitem além do acesso de toda população, uma união de faixas etárias, ritmos e 
intenções diferentes nesses espaços. Porém, nem todas as pessoas possuem poder aquisitivo para frequentar uma academia particular, passando a usufruir dos benefícios nas academias públicas (NOGUEIRA, FERNANDES. 2013).

O Programa Academia da Saúde, cujo objetivo principal é contribuir na promoção de saúde da população a partir da implementação de polos com infraestrutura, equipamentos e quadro de pessoal qualificado para orientar as práticas corporais, atividade física, lazer e modos de vida saudável possibilitou a popularização de equipamentos de ginástica nos espaços públicos. O Programa elenca onze objetivos específicos, dos quais se destaca a contribuição no sentido de ampliação de espaços sociais de lazer na proposta de inclusão social, o enfrentamento da violência e a melhora das condições de saúde e qualidade de vida (BRASIL MINISTÉRIO DA SAÚDE, 2013).

O projeto arquitetônico dos polos é responsabilidade das gestões municipais, considerando clima, cultura, região e características físicas sendo vetado ao município fazer qualquer supressão nas diretrizes do projeto, fornecidas em manual instrutivo do processo de projeto e construção dos polos. O investimento é feito em diferentes modalidades, sendo elas: básica, intermediária e ampliada, as variantes são a metragem quadrada e a infraestrutura exigida, como sanitários, depósitos e etc. (BRASIL MINISTÉRIO DA SAÚDE, 2013).

Com fomento do investimento do Ministério da Saúde e a ampla aderência dos municípios pelo programa, o número de equipamentos de ginástica de uso público teve expressivo crescimento nos últimos anos, tornando o programa de academias ao ar livre (AAL) cada vez mais importante no tempo de lazer das pessoas. Porém, podese, ao observar a cidade, perceber que alguns polos de AAL necessitam de melhorias e adequações, de forma a possibilitar real qualidade de vida para as pessoas que o utilizam, corroborando que apenas o fornecimento dos equipamentos não é suficiente uma vez que, sem ambiente e manutenção adequados, o investimento se torna um desperdício.

Os equipamentos, assim como o pólo no qual são inseridos, necessitam atender diferentes públicos. Concomitante à instalação dos equipamentos acontece uma crescente preocupação no sentido de que princípios mínimos de ergonomia, de conforto, de segurança, design universal aspectos de segurança, satisfação, usabilidade e acessibilidade destes equipamentos e pólos sejam atendidos (OLIVEIRA, 2014).

A Associação Brasileira de Ergonomia define Ergonomia (ou Fatores Humanos) como uma disciplina científica relacionada ao entendimento das interações entre os seres humanos e outros elementos ou sistemas e à aplicação de teorias, princípios, dados e métodos a projetos a fim de aperfeiçoar o bem estar humano e o desempenho global do sistema (ABERGO, 2013).

Design universal significa a concepção de produtos, ambientes, programas e serviços a serem usados, até onde for possível, por todas as pessoas, sem necessidade de adaptação ou projeto específico. $O$ 'desenho universal' não excluirá as ajudas técnicas para grupos específicos de pessoas com deficiência quando necessárias 


\section{(CONVENÇÃO INTERNACIONAL SOBRE DIREITO DAS PESSOAS COM}

DEFICIÊNCIA. 2006).

A NBR 9050 da ABNT, que dispõe sobre a acessibilidade em edificações, espaços, mobiliários e equipamentos urbanos, define que "acessibilidade é a possibilidade e condição de alcance, percepção e entendimento para utilização com segurança e autonomia de edificações, espaço, mobiliário, equipamento urbano e elementos" (NBR 9050, 2015).

Essas características físicas dos equipamentos, e atributos espaciais capazes de garantir as definições citadas, são determinantes ao amplo uso, que se estenda a toda população sem exclusões e sem causar dificuldades e constrangimentos.

\section{CARACTERIZAÇÃO ESPAÇOS PÚBLICOS E AMBIENTES AVALIADOS.}

Os espaços públicos e a vida pública remetem à acessibilidade e apropriação dos espaços, que são concretos e referem-se à política e à cultura. Praças, ruas, avenidas, jardins, parques constituem os espaços abertos das cidades, que representam ideais de diferentes momentos históricos, e não podem ser debatidos apenas a respeito de suas diferenças de escalas. Esses espaços possuem inserção urbana, funções e usos diversos e, consequentemente, precisam de projetos de natureza diferentes (SUN ALEX, 2011).

As praças públicas podem ser definidas como espaços públicos urbanos, propícios à convivência e ao lazer, sem edificações (VIERO E BARBOSA FILHO, 2009). São pontos de encontro e comumente dispõem de atrativos voltados ao lazer e ao esporte. Macedo e Borba (2002, apud VIERO e BARBOSA FILHO, 2009), classifica-se esses locais de acordo com suas espacialidades.

No caso da Presidente Médici, no bairro Bom Pastor, classifica-se como Praça Jardim, por possuir vegetação e desenho paisagístico que prioriza a circulação e o contato com a natureza, podendo esses espaços ser fechados ou abertos e margeados por construções comerciais e residenciais.

Apesar do entendimento de acesso e fluxo livres existem, também, os espaços públicos controlados, com acesso e circulação monitorados, os edifícios como Prefeituras, instituições de ensino, hospitais ou espaços abertos como o campus universitário, que comporta uma das academias em análise. Esses espaços controlados, apesar de oferecerem a liberdade do uso público, se limitam em questões de horários e, de certa forma, se tornam mais conservados e com manutenção mais eficaz, já que existe a inibição a práticas de vandalismos e usos marginalizados.

O potencial de abrangência, quanto à apropriação dos espaços públicos, vem sendo fortemente cerceado pela difusão do medo, associado à violência urbana. Dessa forma, a disseminação de diversões em ambientes fechados e controlados por aparato de segurança e, consequentemente, seletos e excludentes, vem alterando costumes, repercutindo em mudanças nas relações sociais referentes aos espaços públicos (MENDONÇA, 2007). 
Os espaços públicos também se referem às ruas, avenidas e becos. No caso de espaços públicos de vias, como a Avenida Brasil, a característica principal é de espaço de circulação, o que a define e a torna um percurso urbano. É indispensável hoje, um lazer encarnado na cidade, identificado na sua dimensão pública, um grande instrumento anti exclusão, uma alternativa em que o lazer é peça chave para a harmonia e inclusão social (ROLNIK, 2000).

Atualmente, a permanência no espaço público é composta por pessoas que não possuem moradia, de baixo poder aquisitivo e que vivem nesse espaço como meio de sobrevivência.

Para Rolnik (2000), "a medida que o processo de homogeneização, de fragmentação, de isolamento se torna mais exacerbado, áreas que ficam abertas são ocupadas por destituídos, mendigos, miseráveis, marginais, enfim, excluídos".

O conflito conceitual entre o que difere os espaços públicos ao qual é comparada a eficiência das estruturas de AAL passa por esse crivo de realidades.

Enquanto a praça possui sua vizinhança próxima, que efetiva a relação de pertencimento e tem o espaço como constituinte da identidade de morar em suas vivências, o trecho com equipamentos da Avenida Brasil é isolado da relação de vizinhança, sendo limitado fisicamente pelo fluxo dos veículos e ainda pela marca natural da paisagem constituída pelo rio Paraibuna, a pista de corrida, que forma o circuito da avenida é improvisada e a presença dos atores sociais excluídos marginalizados é muito mais intensa. No caso do Campus, a pluralidade do espaço e segurança local, permitem identificar, inicialmente, que o espaço controlado inibe violências, vandalismos porém, inibe também a presença de realidades sociais identificáveis nos outros suportes de espaços públicos.

\subsection{Academia Ao ar livre no Campus da UFJF}

O Campus da Universidade Federal de Juiz de Fora situa-se na zona oeste. Os bairros São Pedro e Martelos são a locação central do campus, sendo a população estimada da área de 15.200 pessoas (IBGE, 2010).

Essa região conformada na zona oeste é chamada Cidade-Alta, engloba bairros com formações e concepções urbanísticas diferenciadas, gerando uma complexa organização sócio territorial onde parte dos impactos locais se relaciona aos conflitos sociais e dificuldades para a organização coletiva dos movimentos. Recebeu nos últimos anos investimentos públicos e privados, configurando-se como área de expansão imobiliária (GERALDO, 2016).

A Academia ao Ar Livre da UFJF foi a primeira implantada em Juiz de Fora, finalizada no ano de 2010, estando localizada no conjunto central do Campus ao lado da Praça Cívica (figura 1). O complexo funciona articuladamente com um parque infantil, pista de skate com espaço de 350 metros e uma área de caminhada, corrida e ciclovia, com percurso de 2.200 metros. Toda a comunidade tem acesso para utilização dos equipamentos nos turnos de manhã, tarde e noite, inclusive aos finais de semana, com restrição neste caso, de horários noturnos. A Academia é equipada com 13 aparelhos, sendo que a maioria pode ser utilizada por duas ou mais pessoas simultaneamente. 

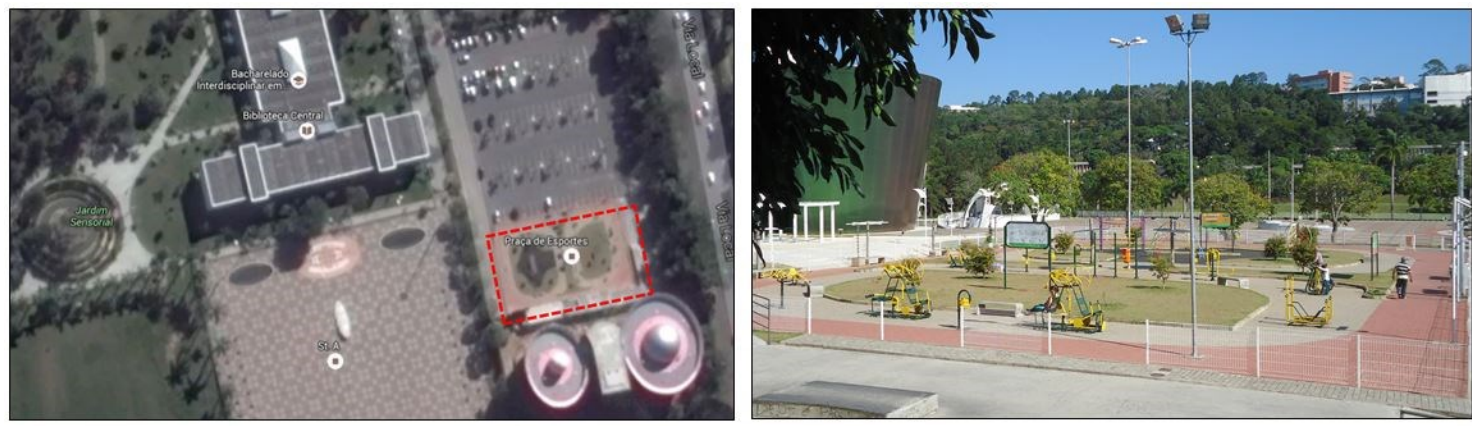

Figura 01: Imagem A, Locação Academia ao ar livre, Google mapas, destaque em tracejado. Imagem B, Campus da UFJF. Fonte: Autores

A Faculdade de Educação Física (Faefid) é responsável pelo projeto "Academia ao $\mathrm{Ar}$ Livre", que é desenvolvido em parceria com a Unimed. Por mês, cerca de 200 pessoas são assistidas pelo projeto. Há orientação gratuita para os usuários de segunda a quinta e aos sábados.

Os acessos aos equipamentos da academia se dão por rotas pavimentadas de blocos permeáveis intertravados e, em casos de ligação com o pátio de estacionamento, com manta asfáltica. A academia possui cercamento por gradis de ferro, com altura de 1,10 metros, o que proporciona segurança ao permanecer na área, impedindo conflitos com fluxos de skate, carros, bicicletas, patins além de ser uma proteção e controle das crianças que utilizam do parque infantil ao lado da academia de ginastica.

Os aparelhos possuem fixação em concreto e não possuem marcas de desgaste de uso ou de fatores climáticos, A sinalização é presente no espaço, as placas com instruções de uso dos equipamentos são de boa visibilidade. Não existem desníveis ou obstáculos do piso, como degraus, a não ser nas divisões que separam a área de circulação dos canteiros gramados. Não existem pisos táteis direcionais nem pontos de instrução em braile. A integração com os demais equipamentos do campus coloca a estrutura do espaço completa, com banheiros, bebedouros, mesas e bancos, lixeiras de coleta seletiva. Existe iluminação direcional para carros e pedestres, o que proporciona a utilização dos equipamentos também a noite. $O$ campus possui arborização diversificada sendo que áreas de acesso público são equilibradas com pontos de sombreamento e insolação.

\subsection{Academia ao Ar livre na Praça do Bom Pastor (Praça Presidente Médici)}

O bairro Bom Pastor, situa-se na Zona Sul de Juiz de Fora, próximo ao triangulo central de formação do município. Com a ocupação majoritariamente residencial, conta com uma paróquia, um clube e com algumas agências de publicidade, escritórios de arquitetura e um pequeno centro comercial. A população, considerada de classe média, é de. Aproximadamente. 6.500 habitantes.

A Praça Presidente Médici, localiza-se na parte central do bairro, medindo aproximadamente $14000 \mathrm{~m}^{2}$, margeando o Clube Bom Pastor, em um nicho circundado por três vias, sendo elas Av. Dr. José Procópio Teixeira, Rua Dr João Penido Filho e Rua Cristóvão Malta (figura 2). 
Além disso, as ruas periféricas também possuem fácil estacionamento. A praça conta com pista de caminhada pavimentada, parque infantil cercado. $O$ traçado paisagístico divide a área em canteiros gramados, passagens pavimentadas com blocos intertravados e áreas de saibro. A arborização da praça é composta por espécies variadas, na sua maioria de médio porte.
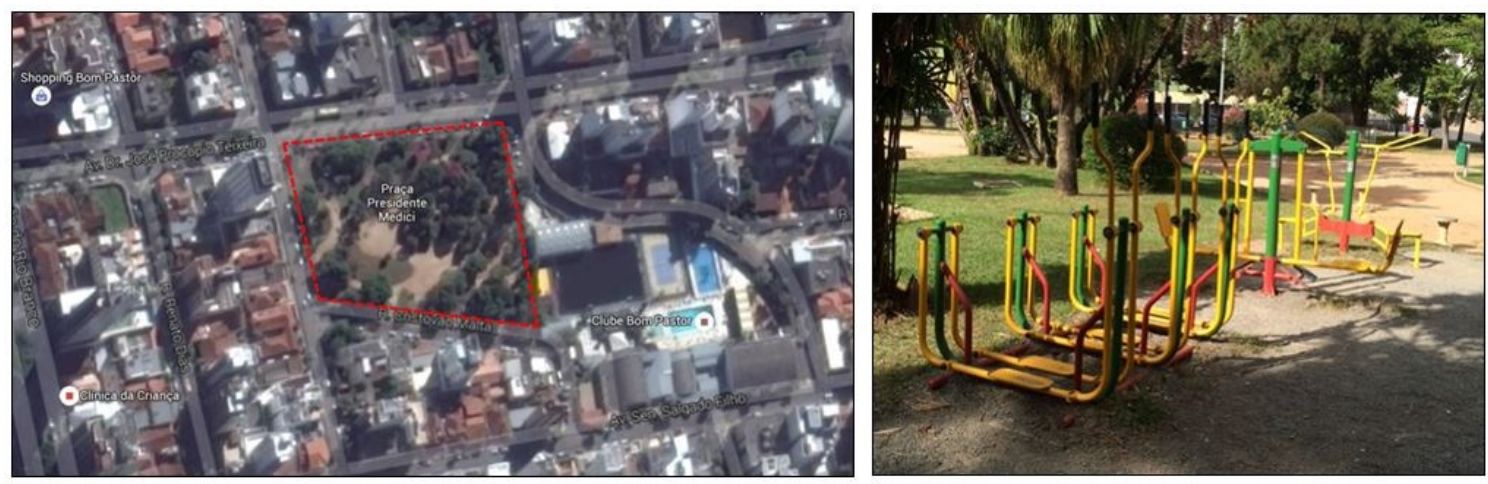

Figura 02: Imagem A, Locação Academia ao ar livre, Google mapas, destaque em tracejado. Imagem B, Praça Presidente Médici. Fonte: Autores

A AAL da Praça Presidente Médici, foi a implantada por iniciativa da prefeitura de Juiz de Fora, no ano de 2012, é localizada no vértice da praça. É composta por nove equipamentos. A fixação dos equipamentos foi executada em um dos canteiros gramados e, com o uso, deu-se o desgaste do solo. Para uma solução paliativa o terreno foi coberto com brita, sendo notável o desnivelamento do local. A AAL não conta com placas informativa para instrução de uso dos equipamentos.

Toda a comunidade tem acesso para utilização dos equipamentos 24 horas por dia, todos os dias da semana, sendo a praça pública e aberta. A Empresa Municipal de Pavimentação e Urbanização - EMPAV é um órgão da administração indireta do município, ligada à Secretaria de Obras, sendo responsável pela manutenção da praça e de seus equipamentos. Não existem acompanhamento e orientação de profissionais na academia sendo isto relatado como um dos problemas pela vizinhança.

\subsection{Academia ao Ar livre na Avenida Brasil}

O Bairro Botanágua fica localizado na Zona Leste de Juiz de Fora, margeando a região central do município. Sua ocupação é composta por uma área residencial, que conta com diversos tipos de equipamentos de serviço e comércio. A população é considerada de classe média e tem, aproximadamente, 1.353 habitantes (IBGE, 2010). A AAL, nesse trecho da Avenida Brasil, faz parte da implantação de mais cinco academias ao longo da via, feita por iniciativa da Prefeitura de Juiz de Fora, entre os anos de 2012 e 2013. O pólo em análise é localizado no cruzamento da Avenida Brasil com a Rua Halfeld, bordeada à esquerda pelo Rio Paraibuna (figura 03).

$O$ fato de a avenida ser utilizada como pista de caminhada e corrida gerou a inserção dos equipamentos e esse ponto específico foi utilizado para observação por sua maior centralidade e proximidade com a área mais ativa, sendo a Rua Halfeld uma das principais vias da cidade.

O espaço possui aproximadamente $25 \mathrm{~m}^{2}$ e conta com seis equipamentos de ginástica sendo que três deles estão impossibilitados de ser utilizados por estarem incompletos. 
A arborização do espaço é composta por espécies de médio porte, e a poluição do rio Paraibuna é uma característica gritante, tornando desconfortável a proximidade com o espaço.
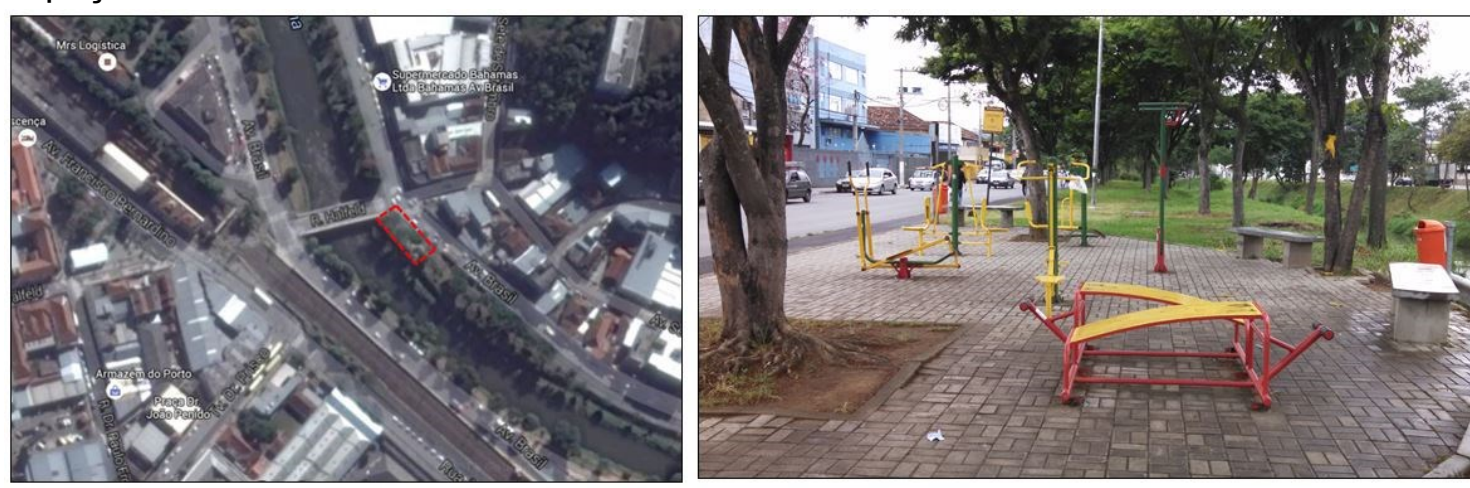

Figura 03: Imagem A, Locação Academia ao ar livre, Google mapas, destaque em tracejado. Imagem B, Praça Presidente Médici. Fonte: Autores

Em observação in loco, foi comprovado que a fixação dos equipamentos foi executada corretamente e sobre pavimentação em blocos intertravados, sendo que ao longo da margem da Avenida Brasil existe um percurso em pavimentação asfáltica e sob a margem do Rio Paraibuna uma área gramada.

A AAL conta com placas informativas para instrução de uso dos equipamentosestando, no entanto, danificadas, o que dificulta sua utilização. O estado de conservação dos equipamentos é regular, possuindo deterioração, ferrugem e falta de alguns acessórios. Não existem acessos com pisos direcionais e nem instruções em braile, a infraestrutura local conta apenas com bancos de concreto e lixeiras, estando ausente recolhimento seletivo. O acesso e utilização dos equipamentos da academia podem ser feitos 24 horas por dia. Não existem profissionais responsáveis para instrução nas atividades realizadas nos equipamentos. A EMPAV, citada anteriormente, também é o órgão responsável pela manutenção.

\section{APRESENTAÇÃO DE RESULTADOS}

Ao identificar a intensa presença das academias ao ar livre na cidade de Juiz de Fora e a frequência com que os equipamentos de ginástica são encontrados nos mais diversos tipos de espaços, foi elaborada uma busca nos noticiários locais sobre a dinâmica em que a população informa e é informada sobre as AAL. Não foram raros os casos em que os jornais de circulação municipal anunciaram reclamações de diversos bairros sobre a segurança, estado de conservação e precariedade dos equipamentos instalados, assim como ausência de equipe profissional a instruir os usuários, a exemplo, a reportagem de 14 de junho de 2016, no jornal Tribuna de Minas, que destaca a matéria "Academias longe de serem esportivas", que narra os inúmeros problemas de conservação e manutenção dos equipamentos presentes no circuito da Avenida Brasil. Sequentemente ao conhecimento de que a manutenção nos espaços é um dos problemas que mais ressalta na opinião da comunidade, foram realizadas visitas nos pontos escolhidos para elaboração de análise aproximada, relações espaciais e informações que narrem a dinâmica que o projeto do Ministério da Saúde agrega aos espaços. 
As análises nos pólos AAL no Campus da UFJF, da Avenida Brasil e na Praça Presidente Médici, no Bom Pastor, aconteceram nos meses de maio e junho de 2016, totalizando três visitas nos turnos da manha, tarde e noite. Com relação à comparação dos diferentes espaços, como resumido no Quadro 1, as modalidades de instalação dos equipamentos foram de investimento básico, sendo a AAL da do Campus Universitário a única que possui investimento de iniciativas públicas e privadas, funcionando com estrutura de profissionais qualificados instruindo e acompanhando os usuários. A Academia da Avenida Brasil é a de menor dimensão, dividido pelo percurso da via, sendo que esse espaço representa $1 / 6$ do investimento da estrutura.

\begin{tabular}{|c|c|c|c|c|c|c|c|}
\hline $\begin{array}{l}\text { Espaço } \\
\text { Público }\end{array}$ & $\begin{array}{c}\text { Modalidade } \\
\text { AAL }\end{array}$ & $\begin{array}{c}\mathrm{N}^{\circ} \\
\text { Aparelhos }\end{array}$ & $\begin{array}{c}\text { Área } \\
\text { Espaço }\end{array}$ & $\begin{array}{c}\text { Área } \\
\mathrm{m}^{2}\end{array}$ & $\begin{array}{c}\% \text { do } \\
\text { espaço }\end{array}$ & $\begin{array}{c}\text { Diversidade } \\
\text { Equipamentos }\end{array}$ & Iniciativa \\
\hline $\begin{array}{c}\text { Campus } \\
\text { UFJF }\end{array}$ & Básica & 13 & $\begin{array}{c}14.000 m^{2} \\
\text { Aprox. }\end{array}$ & $\begin{array}{c}740 \\
m^{2}\end{array}$ & $5 \%$ & 13 & $\begin{array}{l}\text { Público/ } \\
\text { Privada }\end{array}$ \\
\hline $\begin{array}{l}\text { Praça } \\
\text { Bom } \\
\text { Pastor }\end{array}$ & Básica & 09 & $14.000 \mathrm{~m}^{2}$ & $96 m^{2}$ & $0,7 \%$ & 06 & Pública \\
\hline $\begin{array}{c}\text { Avenida } \\
\text { Brasil }\end{array}$ & Básica & 06 & $\begin{array}{c}12 \mathrm{Km} \\
\text { Percurso }\end{array}$ & 25 & 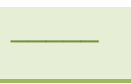 & 06 & Pública \\
\hline
\end{tabular}

$\mathrm{Na}$ academia ao ar livre do Campus da UFJF, além do levantamento das características espaciais, foram aplicados 27 questionários aos usuários que utilizavam o espaço, sendo $70 \%$ mulheres e $30 \%$ homens. Desses usuários, $62 \%$ relataram frequentar a academia de duas a três vezes por semana, $25 \%$ menos de uma vez por semana e $13 \%$ mais que três vezes por semana.

Mais da metade, $66 \%$ desses usuários frequentam o local com intenção de vivenciar lazer e o esporte, $55 \%$ dos usuários residem nos bairros adjacentes ao Campus, sendo o restante residente dos bairros centrais como Grambery, Centro e outros. $O$ meio de transporte mais frequente foi a pé, sendo resposta de $55 \%$ do total, enquanto $37 \%$ acessam o campus através de transporte público e os $8 \%$ restantes utilizam de veículos pessoais.

De forma unânime, os usuários consideraram o espaço da AAL Bom. Sobre conforto, o entendimento de bom foi $63 \%$ das respostas, enquanto $37 \%$ considerou regular, destacando como árido o local, sendo em dias quentes complicado utilizar os equipamentos assim como impossível nos dias de chuva.

A conservação foi considerada Boa em $100 \%$ das respostas, assim como todos os usuários alegaram já terem utilizados os equipamentos. Quanto a Faixa etária, entre as mulheres, $58 \%$ tinham entre 49 e 55 anos, sendo aposentadas ou ausentes do mercado de trabalho, com exceção de uma que se ocupa de atividade comercial, as outras $42 \%$, possuíam entre 17 e 26 anos, e se identificaram como estudantes. Entre o público masculino, $62 \%$ possuíam 55 anos ou mais e se identificaram como aposentados, e $48 \%$ possuíam entre 22 e 30 anos.

Quando consultados sobre quais aspectos a AAL poderia dispor para aperfeiçoar o uso, um usuário apontou que uma cobertura, mesmo que de estrutura vazada, em formato de pérgola, ou vegetação média, que propiciasse sombreamento seriam muito 
bem vindas. Outro apontamento nesse sentido foi de instalarem tendas ou estruturas temporárias para períodos chuvosos que ajudassem aos usuários a não perderem a rotina da prática de exercícios, enquanto outro usuário destacou que existe certa distância entre a área de exercícios e os banheiros e bebedouros, sendo isso um problema para os idosos que demoram a ter acesso a esses espaços. Foi apontado o parque infantil que divide espaço com a academia, como uma característica especial, que torna mais ativa a movimentação local e alguns dos idosos apontaram como extremamente alegres por terem contato com as crianças.

$\mathrm{Na}$ Praça do Bom Pastor foram aplicados 15 questionários. Entre os entrevistados eram $60 \%$ mulheres, entre 45 e 67 anos, que alegaram como ocupação profissional serem profissionais liberais, ou ainda como donas de casa. Dos homens, entre 32 e 71 anos, $35 \%$ se identificaram como aposentados e os outros $65 \%$ como profissionais liberais.

Perguntados sobre a assiduidade na AAL da praça, $80 \%$ alegou frequentar entre dois ou três dias por semana e 15\% mais de uma vez por semana. Quando perguntados sobre os meios de locomoção para acessar a AAL, $80 \%$ alegou acessar a pé e $20 \%$ de automóvel particular.

A finalidade com a qual visitam o local se dá, para $60 \%$ desses indivíduos com motivação pela saúde, enquanto $20 \%$ buscam a prática de esportes e lazer, e ainda $20 \%$ dessas pessoas alegaram ser um espaço de principalmente socialização. $80 \%$ dos entrevistados alegaram residir no próprio bairro Bom Pastor enquanto $20 \%$ nas proximidades.

Sobre as condições da praça em termos de segurança, $10 \%$ dos indivíduos considera Bom, e $45 \%$ regular; enquanto $45 \%$ dessas pessoas considera a segurança ruim. No requisito de conforto $20 \%$ acham bom, $70 \%$ consideram regular; $10 \%$ ruim. Já sobre a conservação dos equipamentos $5 \%$ deles acham bom, $75 \%$ regular e $20 \%$ ruim.

Sobre o estado de conservação dos equipamentos $60 \%$ consideram regular; $40 \%$ consideram ruim. Quando perguntados sobre modificações necessárias $80 \%$ dos entrevistados fizeram reclamação sobre a conservação da $A A L$, assim com a falta de placas e sinalização para o uso correto dos equipamentos. Outra sugestão de frequente presença foi a necessidade de acompanhamento dos usuários da AAL por profissionais de educação física. A maior parte dos entrevistados demonstrou ligação afetiva com a praça, descrevendo suas dinâmicas e a valorização da vida no bairro através desse espaço livre, que proporciona contato com a natureza assim como com os vizinhos.

Já na Av. Brasil foram aplicados 6 questionários com os usuários, sendo 4 homens, de idades entre 50 e 65 anos, que alegaram serem aposentados e autônomos e 2 mulheres, entre 30 e 40 anos que ocupam atividade comercial.

Desses usuários da AAL, 66\% alegaram frequentar a academia de duas a três vezes por semana e $34 \%$ mais que três vezes por semana. Metade dos usuários frequenta por motivos de saúde enquanto o restante busca a prática de esportes e o lazer. A maioria dos usuários chega ao local a pé, o que permite entendermos que são de bairros próximos, (Vila Olavo Costa, Costa Carvalho e Furtado de Menezes), ou que o 
acesso aos equipamentos faz parte da intenção da caminhada e corrida, comuns na avenida. A segurança e o estado de conservação dos equipamentos de ginástica para $66 \%$ desses usuários é considerado regular e o conforto, para a maioria, é considerado como bom.

Devido o intenso fluxo de automóveis no local, o espaço fica comprometido com a segurança, impedindo a maior utilização por crianças e adolescentes. $O$ uso da academia, como visto, é direcionada ao exercício como complemento as caminhadas e corridas sendo, porém, repetitiva a constatação da presença de moradores de rua que, por não terem alguma escolha ou mesmo pela dicotomia social brasileira, fazem dos equipamentos uma espécie de abrigo, mobiliário ou ponto de encontro.

A imagem marginalizada que o espaço passa e a propagação do medo, é um dos aspectos que os poucos usuários da academia encontrados no local alegam ser influenciadores ao não acesso ao local, sendo a violência um fator que mais os preocupa.

Podemos considerar que essas circunstâncias dificultam a aplicação dos questionários com os usuários da AAL na Av. Brasil, já que estes evitam a parada no local. Desta maneira se faz necessário uma política pública de manutenção e reforma desse espaço que integre a sociedade no ambiente de lazer, como é característico em outros espaços públicos e, além disso, é necessário uma política de segurança que proporcione aos usuários a sensação de conforto, uma boa iluminação direcional, melhor policiamento e monitoramento, além de ser necessário o esforço de mitigar as injustiças sociais e alcançar uma melhor reintegração social dos indivíduos marginalizados.

\section{CONSIDERAÇÕES FINAIS}

As AAL estudadas permitem que, através da observação comparativa, possamos compreender que as políticas de incentivo a saúde e lazer públicos tem se disseminado nas cidades e a presença dessa estrutura, com acesso livre, proporciona à população a chance de vivenciar de forma mais intensa e proveitosa o espaço público, resinificando os lugares e colocando a prática de exercícios físicos auxiliados por instrumentos ao acesso de todas as classes sociais.

Constata-se que a instalação de equipamentos de ginástica aqui estudadas não podem ser consideradas estruturas de AAL, excetuando a no Campus da UFJF, pois não contam com infraestrutura nem acompanhamento de profissionais de forma a propiciar o uso correto na prática dos exercícios, assim como a manutenção e qualificação dos espaços não acontece, sendo os equipamentos relegados ao esquecimento assim como a população que os utilizam.

É necessário considerar que, para que haja o usufruto de todos e integração sócioespacial dos ambientes estudados, é necessário não só no projeto dos equipamentos, mas nos espaços aos quais esses são instalados, sejam considerados os princípios do design universal, da acessibilidade, mobilidade, de projetos que visem a real qualidade de vida dos usuários, manutenção e reforma constantes dos equipamentos e, principalmente, políticas ante exclusão, tendo o lazer como fonte essencial para o alcance desses resultados. 
Além da infraestrutura, como um elemento condicionador de um espaço público de qualidade, destaca-se a unidade de cada local, as especificidades e o tipo de relação que os usuários possuem em cada um dos espaços públicos, essas características nos dizem muito sobre a intenção de utilização, sobre a forma de apropriação e sobre a significância desses equipamentos para os diferentes públicos, o que nos proporciona questionar o entendimento das categorias de investimento como básicos, intermediários e avançados que o Ministério da Saúde prevê que se relacionam com área em metros quadrados, número de equipamentos e etc. Possivelmente, a análise prévia do local, antes da determinação da verba, pode proporcionar entender necessidades específicas e elaborar espaços mais eficazes ao lazer e saúde públicos.

A presente pesquisa espera propiciar estudos aprofundados e capazes de gerar materiais que identifique as necessidades de cada local e de referência para possíveis projetos de qualificação dos espaços públicos com ênfase na saúde e lazer.

\section{REFERÊNCIAS BIBLIOGRÁFICAS}

ABERGO. Norma ERG BR 1002 - Código de Deontologia do Ergonomista Certificado. Disponível em: Acesso em 27 mar 2016.

ALEX, Sun. Projeto da Praça. SENAC SAO PAULO. 2011. 292p.

ASSOCIAÇÃO BRASILEIRA DE NORMAS TÉCNICAS. NBR 9050: Acessibilidade a edificações, mobiliário, espaços e equipamentos urbanos. Rio de Janeiro, 2011.

BRASIL. MINISTÉRIO DA SAÚDE. Portaria GM/MS n $\mathbf{2 . 6 8 4}$, de 8 de novembro de 2013. Redefine as regras e os critérios referentes aos incentivos financeiros de investimento para construção de polos e de custeio no âmbito do Programa Academia da Saúde e os critérios de similaridade entre Programas em Desenvolvimento no Distrito Federal ou no município e o Programa Academia da Saúde. Brasília, 2013a. Acesso em: 10 jun. 2016.

<bvsms.saude.gov.br/bvs/saudelegis/gm/2013/prt2684_08_11_2013.html>.

CAMARGO, Luiz Octávio de Lima. O que é lazer. São Paulo: Brasiliense,2003.

GERALDO, Watuse Mirian de Jesus. Mais aoutores... Agenda 21 Da Região Do Bairro São Pedro. Depto. de Geociências, Curso de Geografia - UFJF. 2016.

MENDONÇA, Eneida Maria Souza. Apropriações do espaço público: alguns conceitos. Estudos E Pesquisas Em Psicologia, UERJ, RJ, v. 7, n. 2, p. 296-306, ago. 2007

NOGUEIRA, Renato Souza. FERNANDES, Vera Lúcia da Costa. O Espaço Saúde E Lazer: A Academia Ao Ar Livre Em Questão. UEPA. 2013.

OLIVEIRA, Sabrina Talita De. Recomendações Para Ampliação Da Usabilidade Das Academias Públicas Para Usuários Cegos E Com Baixa Visão. Curitiba, Universidade Federal do Paraná. 2014. 187p.

ROLNIK, R. O lazer humaniza o espaço urbano. In: SESC SP. (Org.). Lazer numa sociedade globalizada. São Paulo: SESC São Paulo/World Leisure, 2000. 